\title{
EVALUATION OF A PROPOSED CHANNEL ON CIRCULATION AND MORPHOLOGY CHANGE AT KAWAIHAE HARBOR AND PELEKANE BAY, HAWAII, USA
}

\author{
Honghai $\mathrm{Li}^{1}$, Mitchell E. Brown ${ }^{1}$, Nicholas C. Kraus ${ }^{1}$, Thomas D. Smith ${ }^{2}$, and Jessica H. Podoski ${ }^{2}$
}

\begin{abstract}
In an effort to improve the water quality and restore marine habitats in Pelekane Bay (PB), installation of a circulation channel was proposed with the intent of enhancing water circulation in PB through Kawaihae Deep Draft Harbor (KDDH) and flushing accumulated sediment out of PB. This study was conducted to investigate the hydraulics and sediment transport consequences of dredging such a channel. The coupled wave, flow, and sediment transport Coastal Modeling System (CMS) was applied during a non-storm and a typical winter (storms) time interval. CMS results were analyzed and compared between existing condition and channel alternatives. It was found that upon reaching PB, incident waves breaking induces higher water level from wave setup, whereas the breakwater at KDDH inhibits depth-limited breaking and setup, creating a differential in water surface elevation (WSE). The water level rise along the channel was calculated to be 0.01-0.03 m, with WSE in PB being higher. The differential wave setup, found for almost all wave conditions, produces water flow from PB to KDDH in the proposed channel. The temporally averaged along-channel current speed is calculated from 0.07 to $0.2 \mathrm{~m} / \mathrm{sec}$ for the non-storm and storm conditions, respectively. Bay-to-harbor flows will move sediment into the channel, most of which is deposited within $120 \mathrm{~m}$ from PB. For the winter storm conditions, the maximum deposition in the channel was calculated to be approximately between 0.7 and $2.0 \mathrm{~m}$ among the different alternatives. More sand is deposited under the deeper channel alternatives. The channel or bay blockage appears under all channel alternatives before reaching the end of the simulation.
\end{abstract}

Keywords: coastal modeling; coastal inlets; harbors; hydrodynamics; morphology change; sediment transport

\section{INTRODUCTION}

Kawaihae Deep Draft Harbor (hereafter referred to as Kawaihae Harbor) is located on the northwest coast of the Island of Hawaii, HI (Figure 1). Completed in 1959, Kawaihae Harbor consists of a 2,650 ft long breakwater, and a 1,450 ft wide by 1,050- to $1,750 \mathrm{ft}$ long basin that are under the jurisdiction of HDOT. Two small boat harbors, one at the north end of and the other at the southwest corner of the deep-draft harbor, outside the coral fill area, are under the jurisdiction of the State of Hawaii, Department of Land and Natural Resources. The harbor entrance channel is 3,270 ft long, 520 $\mathrm{ft}$ wide, and $40 \mathrm{ft}$ deep. Sediment and coral rubble deposited from the harbor dredging created a 60 acre landfill on the south side of the harbor (HDOT 2009). Kawaihae Harbor has two commercial piers along the northeast rim of the harbor basin. A National Oceanic and Atmospheric Administration's (NOAA) Kawaihae tide gage (1617433) is located between Piers 1 and 2.

As the population grows and the local economy develops in West Hawaii, Kawaihae Harbor is expected to experience rapid development and enhancement. Pelekane Bay, located south of and adjacent to Kawaihae Harbor, receives runoff from the Kawaihae watershed and is sometimes considered as being murky. The bay has served as a historical and cultural center for native Hawaiians, and it is a breeding ground for many indigenous reef fish species.

\section{Background}

Long-term changes in the marine habitat and biota of Pelekane Bay were studied over a 20 year period from 1976 through 1996 (Tissot 1998). Tissot noted that a major decline in the abundance of the marine biota had taken place. Possible causes of this deleterious change were associated with long-term sedimentation due to terrestrial runoff from the Kawaihae watershed and reduced ocean circulation in Pelekane Bay caused by construction of the deep- and shallow-draft harbors.

In an effort to improve water quality and restore marine habitats in Pelekane Bay, installation of a circulation channel connecting Pelekane Bay and Kawaihae Harbor through the coral fill area was proposed with the intent of improving water circulation in the bay through Kawaihae Harbor and, therefore, moving accumulated sediment out of the bay (College of Tropical Agriculture and Human Resources 2001, Tissot 1998).

\footnotetext{
${ }^{1}$ US Army Engineer Research Development Center, Coastal and Hydraulics Laboratory, 3909 Halls Ferry Road, Vicksburg, MS 39180, USA

${ }^{2}$ US Army Corps of Engineers, Honolulu District, Building 230, Fort Shafter, HI 96858-5440, USA
} 


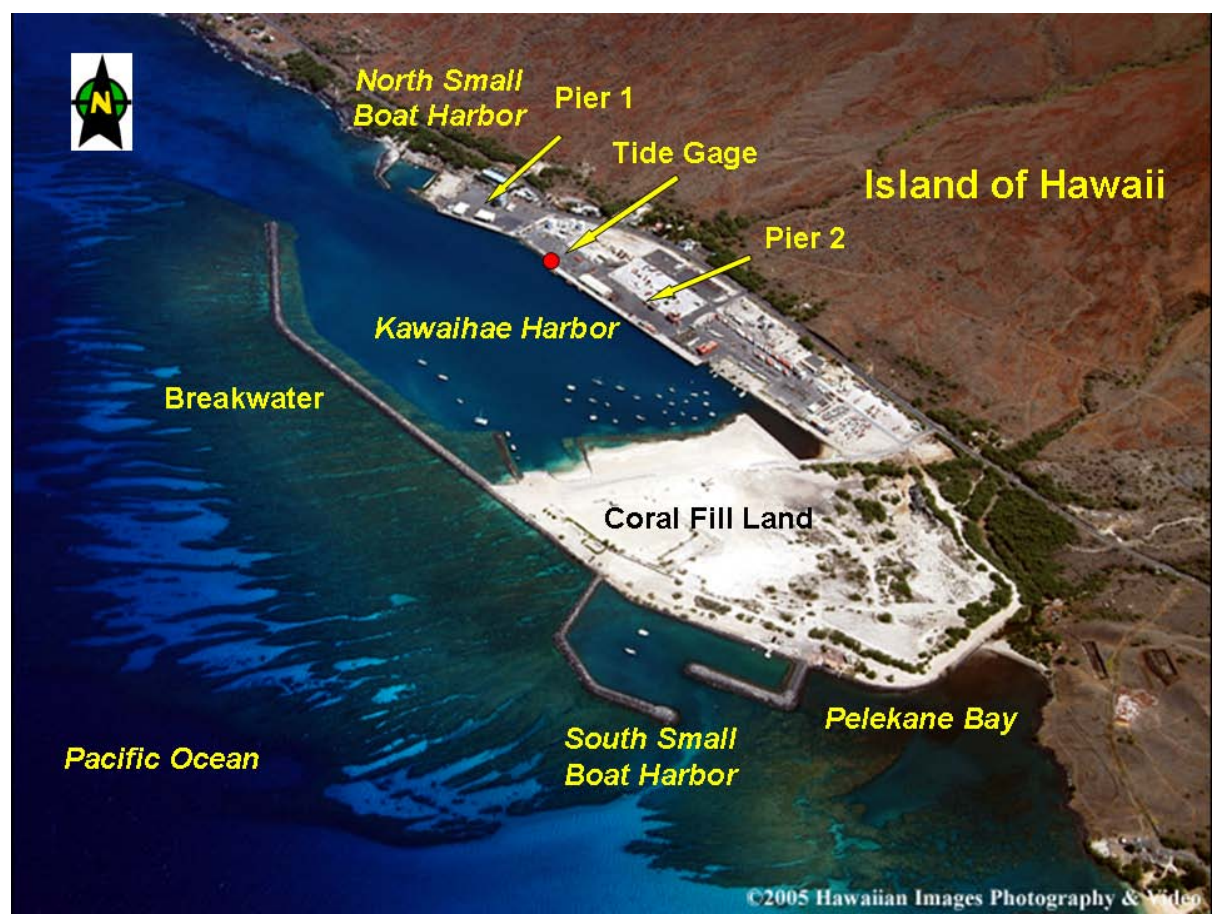

Figure 1. Kawaihae Harbor and Pelekane Bay (Hawaiian Images Photography and Video 2009). The red circle denotes the location of NOAA's Kawaihae tide gage (1617433).

\section{Objectives}

To evaluate the channel installation on water circulation and sediment movement, a modeling tool was proposed for the present study. The objectives of the study were to:

1. Quantify potential functioning of the proposed channel between Kawaihae Harbor and Pelekane Bay.

2. Understand the change in water circulation that the proposed channel would have, sediment transport, and morphology change in the harbor and the bay.

3. Assess changes in the nearshore environment under different wave, tide, and wind conditions.

Based on available resources, the study objectives were judged to be best met through numerical simulation and evaluation of waves, tide, current, and sediment transport. There is a limited amount of information for the site from previous studies and from data collection.

\section{Method}

To achieve the study objectives, the Coastal Modeling System (CMS) was applied (Buttolph et al. 2006; Lin et al. 2008). The CMS interactively calculates wave transformation and wave-induced currents, water level change by tide, wind, and waves, interactive waves and currents, and sediment transport and morphology change. The approach taken for this modeling study is:

1. Assemble and review relevant historical data on bathymetry, tide, waves, wind, and sediment.

2. Select a 15 day period and a 6 month period from October to March for model simulations. The former is considered as a non-storm period. The latter is identified as a typical winter period based on wave climatology and should include multiple winter storms.

3. Drive the CMS with wind, waves and water surface elevation (WSE) data.

4. Develop four alternatives with different dimensions for the proposed channel between Kawaihae Harbor and Pelekane Bay.

5. Analyze and compare model simulation results under the existing conditions and the channel alternatives.

This study proceeded by evaluating hydrodynamic and morphology change associated with the installation of the proposed circulation channel connecting Kawaihae Harbor and Pelekane Bay. Section 2 describes the data used to drive the model. Section 3 provides information on model framework, setup, and alternatives evaluated. Section 4 presents model results for two selected simulation periods, and Section 5 gives the conclusions of the study. 


\section{DATA ASSEMBLY AND ANALYSIS}

\section{Coastline and Bathymetry}

Coastline information for Kawaihae Harbor and Pelekane Bay along the west coast of the Island of Hawaii was extracted for this study from a geo-referenced image file (http://earth.google.com). The aerial photographs used in the study were obtained from Hawaiian Images Photography and Video (2009).

Bathymetry data for the nearshore area surrounding Kawaihae Harbor and Pelekane Bay were provided by the Scanning Hydrographic Operational Airborne Lidar Survey (SHOALS) (Wozencraft and Lillycrop 2002). The SHOALS system fully surveyed the nearshore regions around the harbor and provided high-resolution and accurate bathymetry from the shoreline to a depth of about $115 \mathrm{ft}$, including mapping of the coral reef and harbor area (Thompson et al. 2006). The offshore bathymetry data were obtained from GEOphysical DAta System (GEODAS) database (NGDC 2009).

Figure 2 shows the depth contours, relative to mean sea level (MSL) from the combination of the two datasets for the study domain. With the SHOALS system, the GEODAS database supplements bathymetry data outside the harbor to the $1,400 \mathrm{ft}$ isobath. The figure displays the harbor basin and the harbor entrance channel with depths ranging from 40 to $50 \mathrm{ft}$. An area of about 500-1,000 ft wide and less than $10 \mathrm{ft}$ deep is covered by coral reefs outside the breakwater. The shallow reef area is separated from the Pacific Ocean by a steep slope and deepens to $500 \mathrm{ft}$ within 2,000 to 4,000 ft offshore.

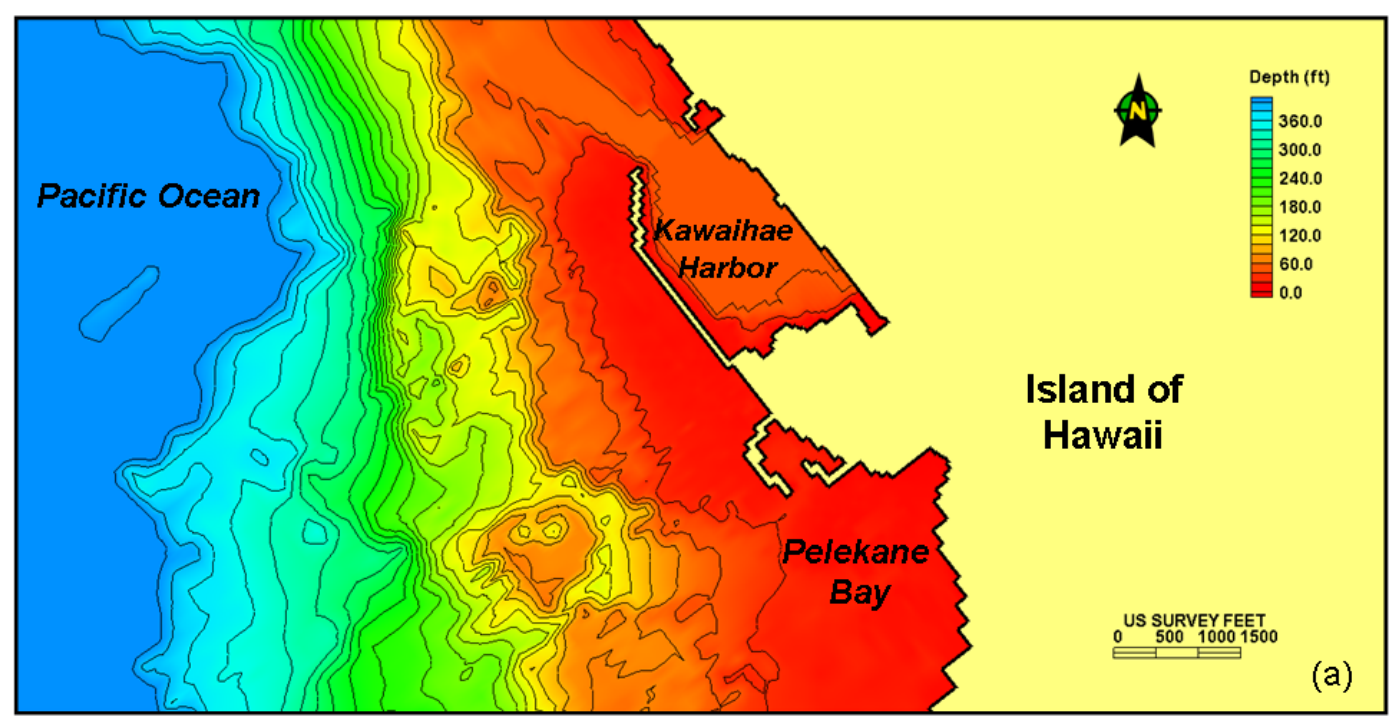

Figure 2. Depth contours (ft) of Kawaihae Harbor and Pelekane Bay (depths to local MSL).

\section{Waves}

Wave data from the National Data Buoy Center (NDBC 2009) and hindcast waves from the USACE Wave Information Studies (WIS) (Coastal and Hydraulics Laboratory 2009) were analyzed (Figure 3).

WIS hindcasts provide wave parameters in the Hawaiian Islands for the years 1981 through 2004. Because the dataset has met the selection criteria for the two simulation periods, it was analyzed and adopted in this study. WIS Pacific Station 113 is the closest WIS station to Kawaihae Harbor (Figure 3). In relation to the geographic location of the project study area, this station is similarly sheltered from northerly waves by the Hawaiian Islands of Maui, Molokai, and Lanai, and from easterly waves by the Island of Hawaii. It does have a wider range of exposure to waves propagating from south-southeast clockwise to northwest.

Wave climatology at WIS Pacific Station 113 (1981-2004) indicates that the predominant waves are from the south-southwest and west-northwest directions. The largest wave heights, occurring at an extremely small percentage (<0.02 percent), are between 15 and $16.5 \mathrm{ft}$. More than 90 percent of the waves are swells that have periods between 10 and $30 \mathrm{sec}$. Those swells mostly correspond to the two 
predominant wave directions, whereas the short-period waves approach the station from east-northeast. The average wave height and peak wave period are $3.9 \mathrm{ft}$ and $12.7 \mathrm{sec}$, respectively.

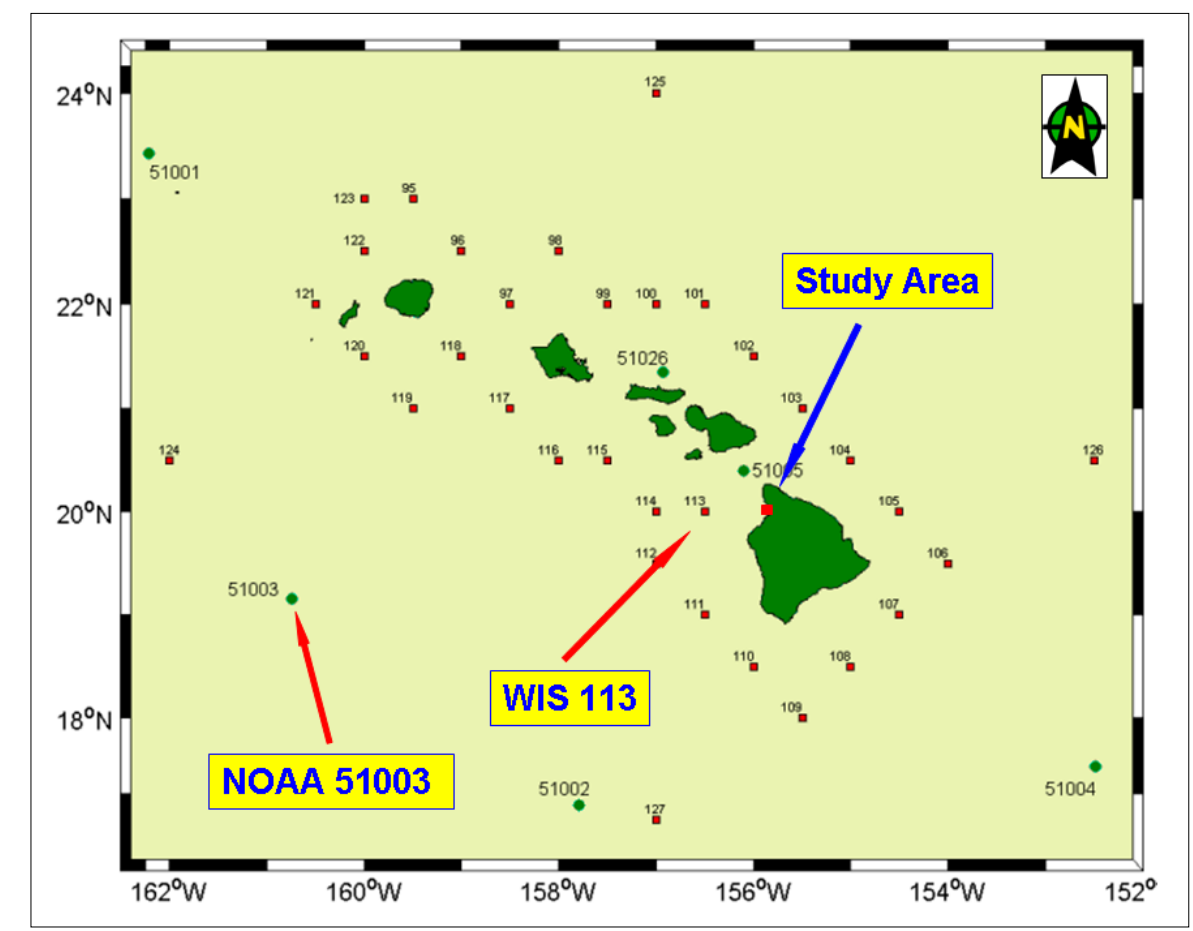

Figure 3. Locations of WIS Pacific stations and NDBC buoys surrounding Hawaiian Islands (large red square depicts the study area).

\section{Water Surface Elevation}

Water surface elevation data for NOAA tide gage 1617433 (Kawaihae, HI) are available on the NOAA website, http://tidesandcurrents.noaa.gov (see Figure 1 for the gage location). Water surface elevation at the gage indicates a mixed, predominately semi-diurnal tidal regime surrounding the study area. The mean tidal range (mean high water - mean low water) is $1.5 \mathrm{ft}$ and the maximum tidal range (mean higher high water - mean lower low water (MLLW)) is $2.2 \mathrm{ft}$. Therefore, the tidal range is considered relatively small in relation to energy produced by large wave incident to the site.

\section{Wind}

Wind data were available from various sources, covering coastal and offshore conditions. Local wind observations were taken from the NOAA station at Kawaihae, HI, and offshore wind data were downloaded from three NDBC moored buoys west (Buoys 51002 and 51003) and south (Buoy 51028) of the Island of Hawaii. Hindcast wind information at WIS Pacific Station 113 was obtained together with the hindcast wave parameters. The wind data were retrieved from the NOAA station and NDBC buoys for year 2004, and the hindcast wind from WIS Pacific Station 113 was for years 1981 through 2004.

There are distinct wind patterns at the onshore and offshore locations in the study area. The 2004 wind direction at the NOAA gage is characterized by either west-southwesterly to west-northwesterly or east-northeasterly to easterly. It was found that the diurnal cycle of the wind direction corresponds well to the sea breeze. A relatively calm coastal region is indicated by the mean wind speed of $9.2 \mathrm{ft} / \mathrm{sec}$ at this location. At the offshore buoy, east-northeasterly to easterly winds are predominant, which is clearly associated with the northeast trade wind system in the region. In relation to the wind at the coastal station, the offshore wind is much stronger, and the mean wind speed is close to $19.7 \mathrm{ft} / \mathrm{sec}$.

\section{Sediment}

Sediment grab samples were taken from the notched area on the southeast side of Kawaihae Harbor over the coral fill area, and on the perimeter of Pelekane Bay on 27 April 2009. Median grain size, $D_{50}$, was determined. The average mean grain size of the six samples is $289 \mu \mathrm{m}$ with a standard deviation of 
33 percent. One large grain size is responsible for the higher standard deviation. Excluding this sample, the average median grain size is $248 \mu \mathrm{m}$ with a standard deviation of 10 percent.

\section{MODELING STRATEGY}

The CMS was applied for simulating waves, circulation, and sediment transport in the study. The hydrodynamic and wave models, CMS-Flow and CMS-Wave, were coupled dynamically in simulating sediment transport and morphology change (Buttolph et al. 2006; Lin et al. 2008).

\section{Model Domain}

In the application of CMS to the Kawaihae Harbor and Pelekane Bay, a variable-resolution grid system was created to discretize the entire harbor, bay, and the offshore region. The model domain extends approximately 8.7 miles alongshore and 5 miles offshore, and the offshore boundary of the domain reaches to the 1,410-ft isobath. Figure 4 illustrates the entire CMS domain, a rectangular grid of $141 \times 167$ cells and bathymetric features of Kawaihae Harbor, Pelekane Bay, and adjoining nearshore and continental shelf. The grid permits much finer grid resolution in areas of high interest such as the back of the harbor, Pelekane Bay, and the coral-fill area of the proposed circulation channel.

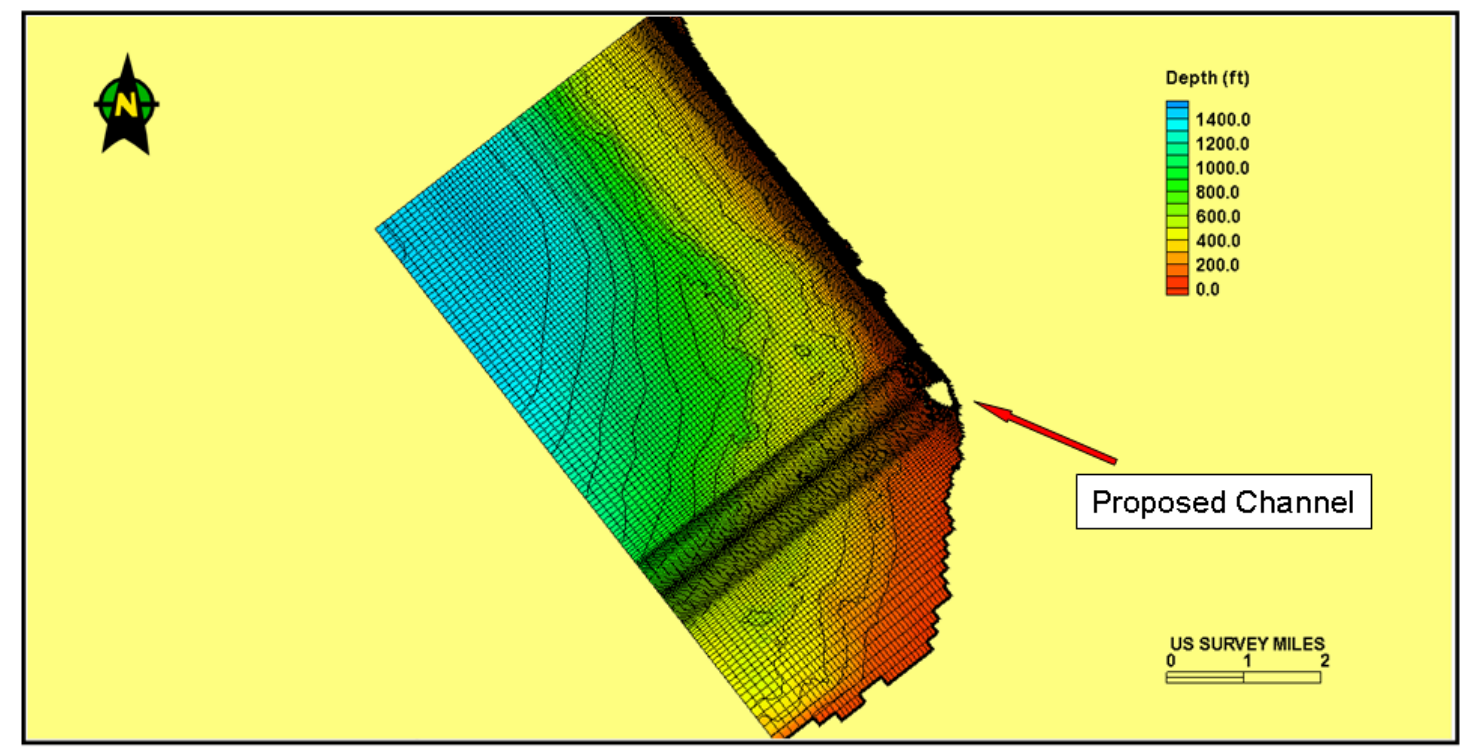

Figure 4. CMS computational grid and bathymetric contours surrounding Kawaihae Harbor, Pelekane Bay, and proposed channel (depths to local MSL).

\section{Simulation Period and Model Forcing}

The model simulations were conducted for both a 15-day, non-storm period and a 6-month, storm period. Based on the WIS dataset, a time period was chosen for the non-storm case from 1-15 April 2004. The mean significant wave height at WIS Pacific Station 113 is $3.9 \mathrm{ft}$ and all wave heights are less than $5.3 \mathrm{ft}$ for this time interval. The mean wave period is $13.9 \mathrm{sec}$, and the predominant wave direction is west-northwest. Clearly, 1-15 April 2004 represents the mean wave condition and corresponds well to a non-storm period at the location.

Selection of the typical winter, storm period, was based on wave climatology. By comparing wave heights, periods, and directions among annual wave data, the representative 6 months were chosen from October 1992 through March 1993. The simulation period spans about 4-5 winter swell events, considering the events produced wave heights close to or exceeding $8.2 \mathrm{ft}$. All those high swells propagate from the west-northwest directions. Aucan (2006) studied wave climatology of the Hawaiian Islands for the years 1957-2002 and identified three to four high-swell events for the 1992-1993 winter season (November-March), indicating that high winter swells were generated by distant North Pacific storms.

The forcing datasets required by CMS-Flow and CMS-Wave come from a variety of sources. The time-dependent water surface elevation data at open boundary locations were specified through water level observations at Kawaihae, HI. Time varying significant wave height, peak spectral wave period, 
and wave direction were based on the WIS hindcasts. Wind forcing data were retrieved from the offshore NDBC Buoy 51003 (Figure 3).

\section{Channel Alternatives}

Bodge and Howard (2006) described the digging of a channel at an island in the North Malé atoll, Maldives. The channel effectively divided the island into two sections. The purpose of the channel construction was to improve water exchange in a semi-enclosed bay, not unlike present study objectives. Forcing of the current through the channel in their coastal engineering study was through a phase difference in the tide on each side of the island, with an average phase difference of 66 sec, giving a $0.16-0.66 \mathrm{ft} / \mathrm{sec}$ flow along the 660 -ft-long channel. In the present study, because Kawaihae Harbor and Pelekane Bay are relatively close as compared to the length of a tidal wave, it was concluded that a differential in water elevation by wave setup or other mechanism related to waves, if present, would have to provide the necessary forcing.

Figure 4 shows the proposed circulation channel connecting Kawaihae Harbor and Pelekane Bay with the CMS grid. To configure the channel for model simulations, tidal level and coastline features around the harbor and the bay were examined. Water surface elevation data at the Kawaihae gage indicate that MLLW is located about $1 \mathrm{ft}$ below MSL. Therefore, two channel depths, 3.3 and $4.9 \mathrm{ft}$ relative to MSL, were specified to assure the channel would be kept wet under different tidal conditions. A dry channel was considered undesirable because potential circulation would be reduced and periodic wetting and drying might tend to promote erosion or deposition. Two channel widths, 98 and $164 \mathrm{ft}$, were selected referring to the scale of the "notched" area on the southeast side of the harbor. As shown in Figure 4, the proposed channel extends about 1,550 ft from the bottom of the notch, through the coral fill, to Pelekane Bay. The harbor and the bay area near the channel's two ends are adjusted to the designed depth for a certain channel configuration if the original depth there is shallower. Four alternatives were developed for the proposed circulation channel.

\section{Simulation Alternatives}

CMS-Flow and CMS-Wave coupled hydrodynamics and sediment transport simulations were conducted for the channel alternatives for the non-storm and storm wave conditions, including tide and wind. Employing WIS waves, five simulations were performed for the non-storm and multi-storm periods, respectively. The primary model parameters selected for those simulations are presented in Table 1.

\begin{tabular}{|c|c|}
\hline \multicolumn{2}{|c|}{ Table 1. Primary parameters for CMS-Flow and CMS-Wave. } \\
\hline Parameter & Value \\
\hline Manning's $n$ & 0.025 \\
\hline Advection & Included \\
\hline Wall Friction & Included \\
\hline Wetting and Drying & Included (Minimum Wet Depth: 0.1 m) \\
\hline Wave Spectral Energy & Half Plane \\
\hline Forward Reflection & 0.5 \\
\hline Wave Breaking & Extended Goda Formula (Goda 1973) \\
\hline Diffraction Intensity & 4.0 \\
\hline Directional Spreading (nn & 20.0 \\
\hline value) & \\
\hline Peak Enhancement Factor $(\mathrm{Y})$ & \\
\hline$D_{50}$ (mm) & 0.25 \\
\hline Sediment Density (kg/m ${ }^{3}$ ) & $2,650.0$ \\
\hline Sediment Porosity & 0.4 \\
\hline Hard Bottom & Partial (in coral reef areas) \\
\hline Transport Equation & Lund-CIRP (Camenen and Larson 2005, 2008) \\
\hline
\end{tabular}




\section{RESULTS AND DISCUSSION}

\section{Non-storm Condition}

\section{Water surface elevations}

Figure 5 shows a snapshot of water surface elevation under Alt 4, surrounding Kawaihae Harbor and Pelekane Bay on 15 April 2004 at 10:00 GMT, when waves approached the study area from westnorthwest. Upon reaching the coral reef area outside the harbor breakwater, and the semi-enclosed and shallow Pelekane Bay, incident waves broke and water level rose due to wave setup, a rise in the mean water surface above the still-water elevation of the sea caused by wave breaking on the beach. The breakwater blocked the waves, so there was no wave setup inside the harbor. Comparing water surface elevations in the offshore region and Kawaihae Harbor, an approximate $0.1 \mathrm{ft}$ setup was produced under this channel alternative outside the breakwater and in Pelekane Bay.

Water surface elevations are also analyzed at four time-series stations denoted as E1, E2, E3, and E4 and located at Kawaihae Harbor, the proposed channel, and Pelekane Bay, respectively, as shown in Figure 5. The computed water surface elevations at Pelekane Bay (E4) over the 15-day simulation indicate that the maximum wave setup occurred under the existing condition in Pelekane Bay. With the channel opening, the setup is less by an average of 0.05-0.07 ft under Alts 2 and 4 , and an average of 0.02-0.03 ft under Alts 1 and 3. Therefore, installation of the proposed channel will result in an alongchannel flow from Pelekane Bay to Kawaihae Harbor and reduce the wave setup in Pelekane Bay.

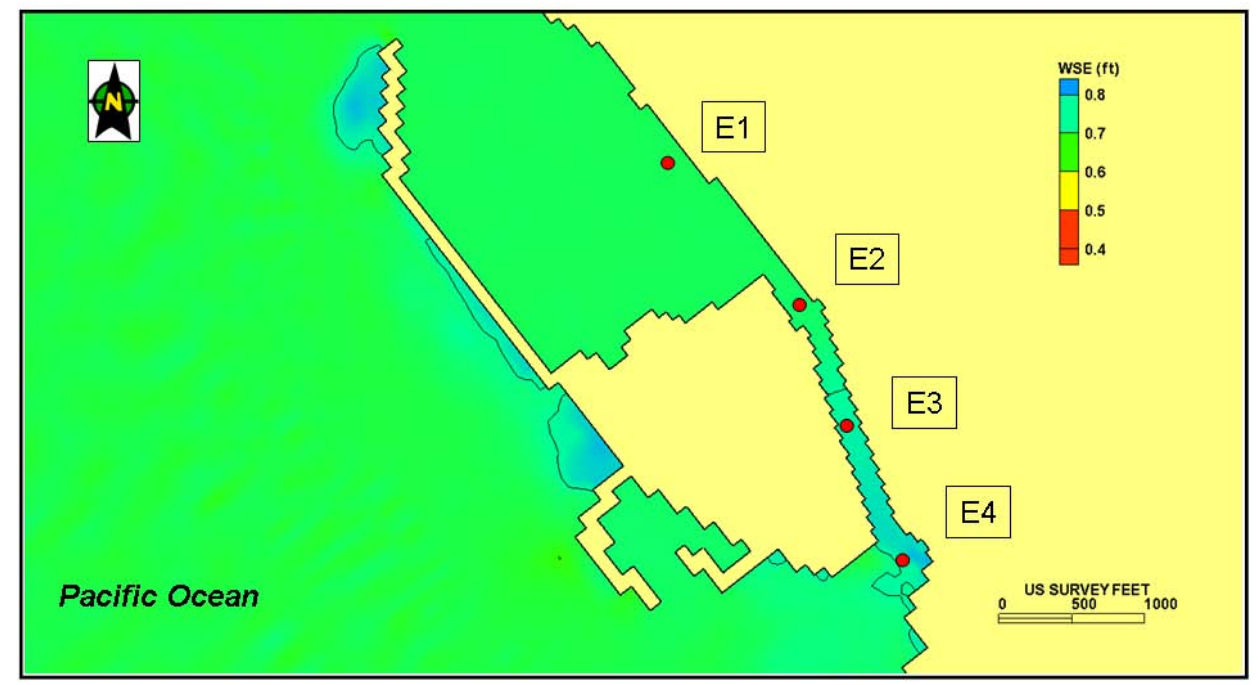

Figure 5. Time series stations in Kawaihae Harbor (E1 and E2), the proposed channel (E3), and Pelekane Bay (E4) (depths to local MSL). CMS-computed water surface elevations under Alt 4 surrounding Kawaihae Harbor and Pelekane Bay during the non-storm period on 15 April 2004 at 10:00 GMT.

Figure 6 plots temporally averaged water surface elevations from the 15-day simulation for the channel alternatives along a section formed by E1 to E4 from Kawaihae Harbor to Pelekane Bay. Inside the harbor at E1, water surface elevation is not affected by the proposed channel. From E2 through the channel to the bay, the water level is seen to rise under the four channel alternatives. Less elevated water levels are presented under the deeper channel alternatives (Alts 2 and 4), and greater elevated water levels under the shallower channel alternatives (Alts 1 and 3). The water rise along the proposed channel shows an average differential wave setup of 0.07-0.1 ft between Pelekane Bay and Kawaihae Harbor, with the water level in Pelekane Bay being higher. Wave setup in Kawaihae Harbor is greatly reduced or absent, because the breakwater prevents depth-limited wave breaking on the beach as at Pelekane Bay and the associated transfer of momentum that raises the water level. 


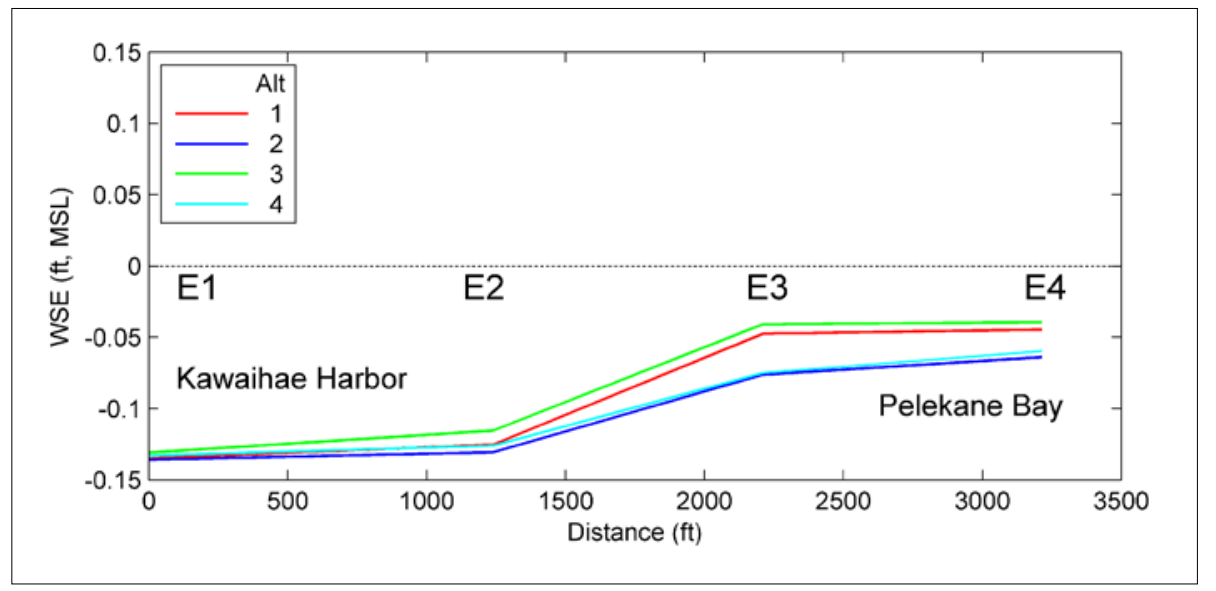

Figure 6. Temporally averaged water surface elevation along section composed of four stations from Kawaihae Harbor to Pelekane Bay, as shown in Figure 5.

\section{Current}

CMS-Flow and CMS-Wave simulations were performed for 1-15 April 2004. Depth-averaged circulation fields surrounding Kawaihae Harbor and Pelekane Bay were retrieved from some snapshots of outputs when relatively large waves were propagating from west-northwest, north-northwest, southsouthwest, and west-northwest, respectively. Figure 7 shows the first snapshot under the existing coastline features.

Under the existing condition, strong currents occur outside the harbor. The current speed is approximately 2.6-3.3 ft/sec along the breakwater over the shallow coral reef area on all occasions. Following the breakwater, the current tends to flow in two directions. The north current travels north passing the tip of the breakwater, meets the alongshore current from the northwest near the harbor entrance channel, and flows away from the harbor. The alongshore current from the northwest splits and produces a weaker current with a speed of $0.33 \mathrm{ft} / \mathrm{sec}$ and continues to flow into the harbor. The southwest current extends toward the south-southwest, and passes the small boat harbor and the outer Pelekane Bay. Interacting with the coastline, this current can have direct contributions to form two anticlockwise gyres outside of Pelekane Bay. The corresponding current speed is between 1.3 and $2.0 \mathrm{ft} / \mathrm{sec}$. In the inner bay, a small, clockwise gyre appears with a weaker current of 0.33-1.0 ft/sec.

Similar flow patterns are presented as waves approach the study area from the west-northwest and north-northwest. The north current becomes stronger and the southwest current weaker as waves propagate from the south-southwest. The comparison demonstrates that wave forcing controls the nearshore circulation near Kawaihae Harbor and Pelekane bay. 


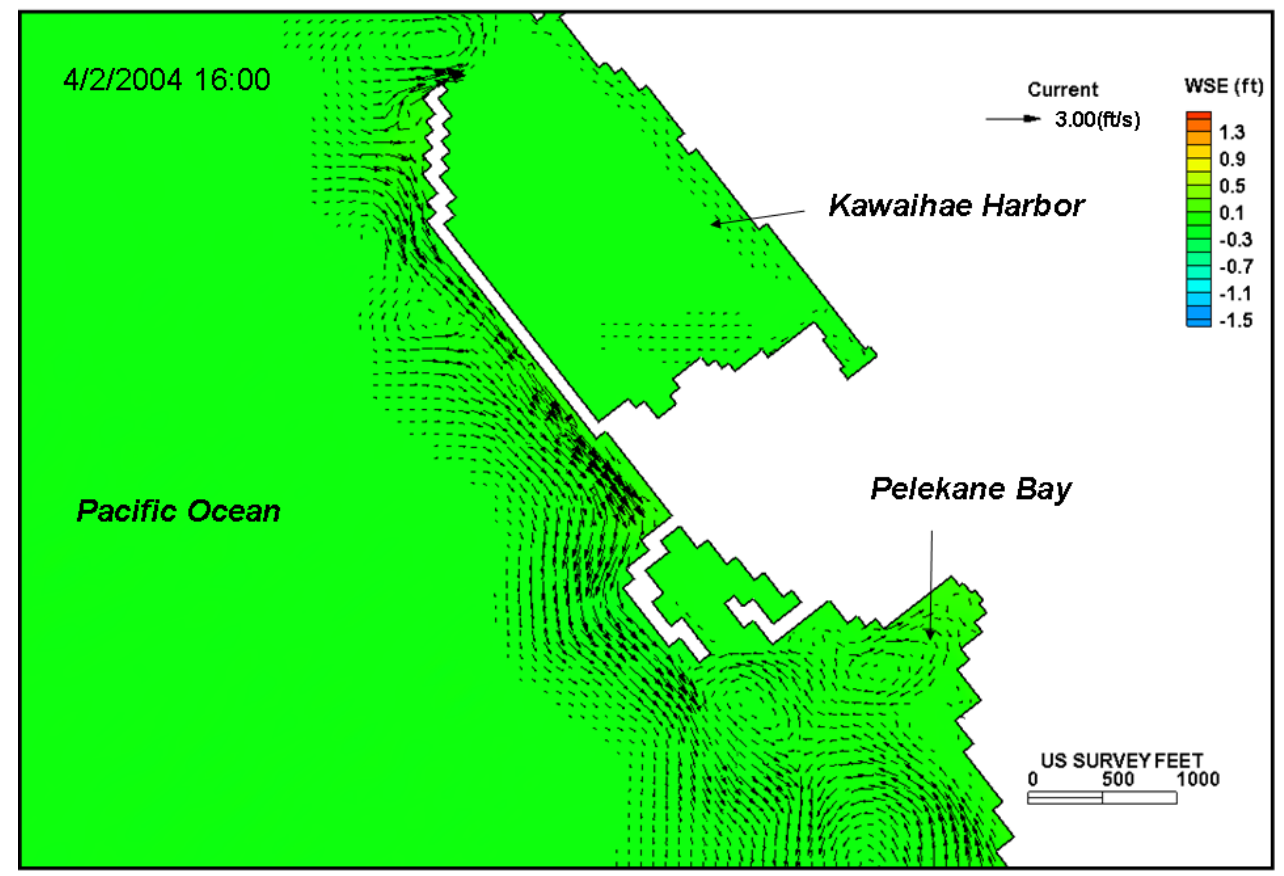

Figure 7. CMS computed depth-averaged current surrounding Kawaihae Harbor and Pelekane Bay under existing condition during 2 April 2004 at 16:00 GMT. Corresponding to this time, significant wave height is $4.5 \mathrm{ft}$, wave period $14.6 \mathrm{sec}$, and wave direction $300 \mathrm{deg}$ azimuth.

Circulation patterns within the harbor, outside the breakwater, and at the outer Pelekane Bay are not affected by installation of the proposed channel. The channel induces a persistent flow from the bay to the harbor. Figure 8 shows the time series of along-channel flow speeds at E2 under Alt 1-4 (positive for the bay-to-harbor direction). During this 15-day period, the along-channel current almost always flows from Pelekane Bay to Kawaihae Harbor. The model domain receives the smallest offshore waves during the early hours of 6 April and waves approach the study area from the north-northeast on 10 April. At these two times the along-channel speed is reduced significantly and the flow directions reverse for a few hours on 10 April. The 15-day averaged speed is $0.36 \mathrm{ft} / \mathrm{sec}$ for Alts 1 and 2, and $0.62 \mathrm{ft} / \mathrm{sec}$ for Alts3 and 4.

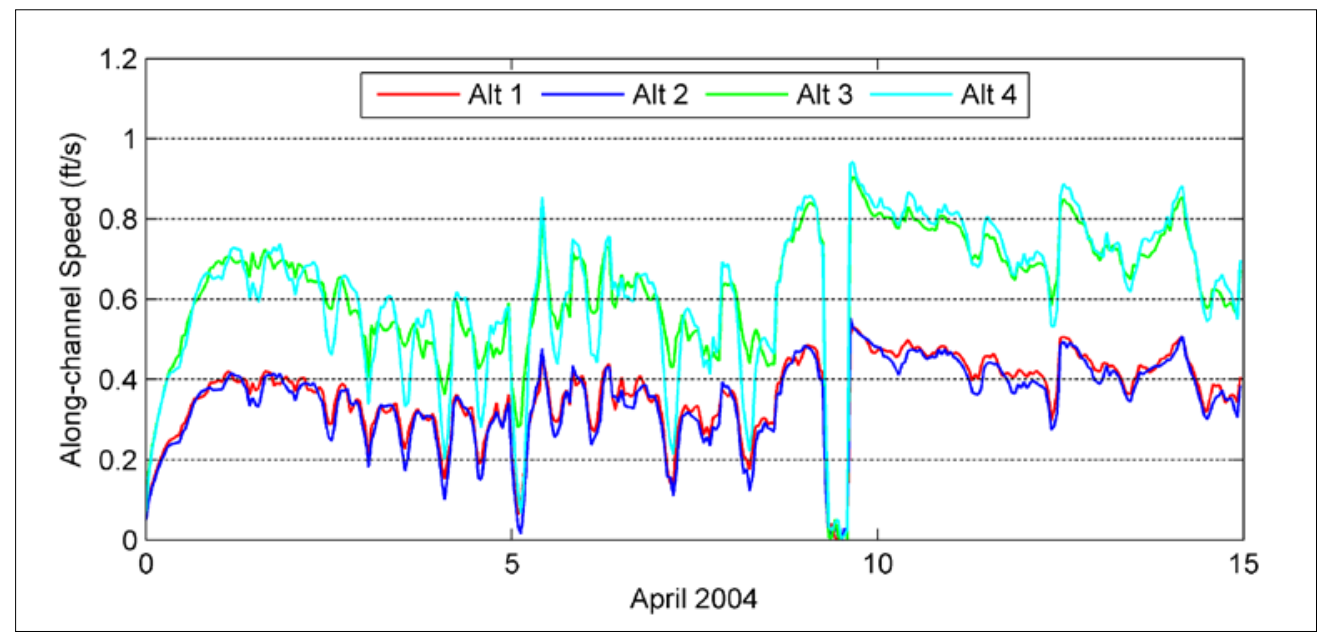

Figure 8. Along channel speed under four channel alternatives. Positive indicates water flow from Pelekane Bay to Kawaihae Harbor.

\section{Sediment transport}

For sediment transport in CMS, the median grain size of $0.25 \mathrm{~mm}$ was specified based on the samples collected in Kawaihae Harbor and Pelekane Bay. The sand bottoms at Pelekane Bay and the notched area on the southeast side of Kawaihae Harbor represented as erodible bottom and the coral cover area and the offshore as hard bottom (non-erodible bottom). 
Morphology changes for the existing condition and Alts 1-4 in the proposed channel and Pelekane Bay are calculated. The spatial distributions in Figures 9 show the results under the proposed channel Alt 1 at the end of the 15-day simulation. Under the existing condition, the erosion is usually followed by immediate deposition in Pelekane Bay. The relatively weak circulation in the inner bay produces less transport of sediment. The channel installation, however, alters the pattern of sediment transport in the bay. Stronger circulation is able to carry eroded sand near the outer bay a longer distance and deposit it in the vicinity of the channel mouth. Persistent current flowing from the bay to the harbor is moving sediment into the channel, most of which is deposited within $400 \mathrm{ft}$ from the bay (Figure 9).

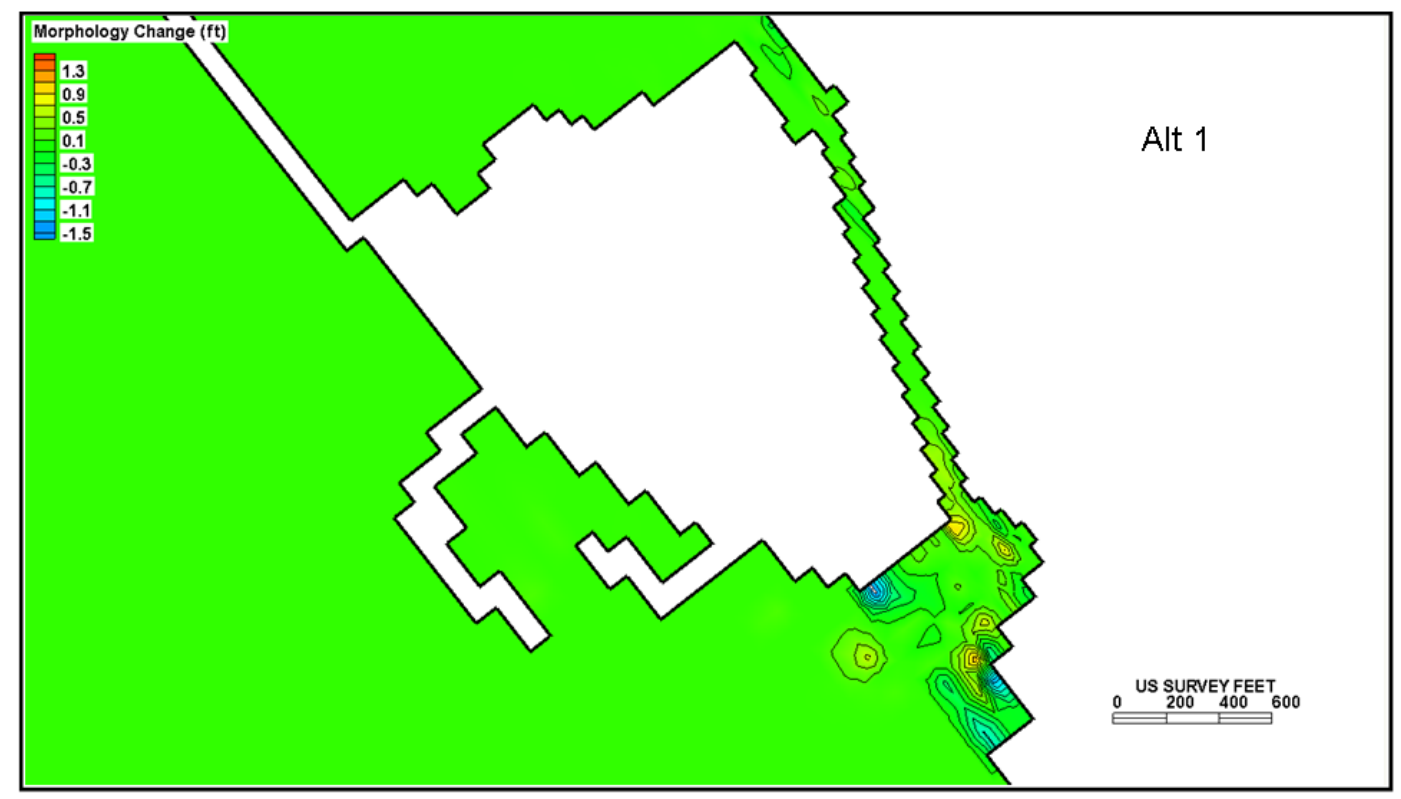

Figure 9. Morphology change for Alt 1 after 15-day simulation.

Table 2 presents the maximum computed erosion and deposition and total sediment volume change in Pelekane Bay and in the proposed channel under the existing condition and the proposed channel alternatives. The maximum erosion is approximately $2.0 \mathrm{ft}$ in Pelekane Bay. The maximum deposition in the channel ranges between approximately 0.4 and $0.9 \mathrm{ft}$ under different alternatives at the end of the simulation. For the same channel depth, a wider channel (Alts 3 and 4) would lead to a 75-80 percent increase in the maximum deposition inside the channel and a 1.6-1.8 times increase in sediment volume transported from the bay into the channel compared to a narrow channel (Alts 1 and 2). Based on the values in the last column of the table, the volume of sand that would have to be dredged from the channel to maintain the designed channel depth is $311 \mathrm{cu}$ yd for Alt 1 and about $900 \mathrm{cu}$ yd for Alt 4. 


\begin{tabular}{|c|c|c|c|c|c|}
\hline Scenario & $\begin{array}{c}\text { Maximum } \\
\text { Erosion in } \\
\text { Pelekane Bay } \\
\text { and Channel } \\
\text { (ft) }\end{array}$ & $\begin{array}{l}\text { Maximum } \\
\text { Deposition in } \\
\text { Pelekane Bay } \\
\text { and Channel } \\
\text { (ft) }\end{array}$ & $\begin{array}{c}\text { Maximum } \\
\text { Deposition near } \\
\text { Mouth of Channel } \\
\text { (ft) }\end{array}$ & $\begin{array}{l}\text { Maximum } \\
\text { Deposition in } \\
\text { Channel (ft) }\end{array}$ & $\begin{array}{c}\text { Sediment } \\
\text { Volume } \\
\text { Transported in } \\
\text { Channel (cu yd) }\end{array}$ \\
\hline Exst & -2.0 & 1.8 & 0.0 & $N / A$ & $N / A$ \\
\hline Alt 1 & -1.6 & 1.1 & 0.9 & 0.4 & 311 \\
\hline Alt 2 & -1.3 & 1.7 & 0.4 & 0.5 & 348 \\
\hline Alt 3 & -1.9 & 1.6 & 0.9 & 0.7 & 857 \\
\hline Alt 4 & -1.6 & 2.3 & 2.3 & 0.9 & 904 \\
\hline
\end{tabular}

Time series of depth change at five selected stations in Pelekane Bay and the proposed indicate a linear increase of deposition. The channel stations have higher deposition rates under Alts 3 and 4 than under Alts 1 and 2; the bay stations have higher deposition rates under Alts 2 and 4 than that under Alts 1 and 3. Assuming that a linear trend of deposition continues at the channel stations, the proposed channel would be filled up within approximate 130, 157, 80, and 119 days under Alts 1 through 4, respectively.

\section{Storm Condition}

Five winter storms were identified for the 6-month storm period from October 1992 through March 1993. Wave parameters of these events are listed in Table 3. Peak wave heights are greater than $7.5 \mathrm{ft}$, and waves approach the study area from the west-northwest direction during each storm. The maximum wave height is approximately $12 \mathrm{ft}$ and occurred on 7 January 1993 at 16:00 GMT. The following analysis of hydrodynamics and sediment transport concerns these five storms.

\begin{tabular}{|c|c|c|c|}
\hline Date (1993) & $\begin{array}{l}\text { Wave Height } \\
\text { (ft) }\end{array}$ & $\begin{array}{l}\text { Wave Direction } \\
\text { (deg, azimuth) }\end{array}$ & $\begin{array}{c}\text { Wave Period } \\
\text { (sec) }\end{array}$ \\
\hline 01/07 16:00 GMT & 11.88 & 302 & 13.1 \\
\hline 01/11 08:00 GMT & 7.97 & 299 & 12.9 \\
\hline 01/30 09:00 GMT & 7.51 & 292 & 12.1 \\
\hline 02/06 23:00 GMT & 8.10 & 304 & 14.8 \\
\hline 03/15 06:00 GMT & 8.46 & 287 & 13.3 \\
\hline
\end{tabular}

\section{Water surface elevation}

Water surface elevations were analyzed at Kawaihae Harbor, Pelekane Bay, and the proposed channel for the four channel alternatives and the existing condition in the 6-month storm period, 1 October 1992 to 31 March 1993. During the five winter storms, Pelekane Bay has higher water elevation under the existing condition than under the channel alternatives except when significant sediment infilling appears in the channel or the bay after 6 January 1993 under Alt 3, 21 February 1993 under Alt 4, and 11 March 1993 under Alt 1. The average water level setup under the existing condition is 0.01-0.06 ft higher than that under channel alternatives during the storms, and 0.01-0.03 ft higher during non-storm times. Comparing the channel alternatives to the existing condition, a deeper channel, Alts 2 and 4, has less water level setup by an average of $0.03 \mathrm{ft}$ and a shallower channel, Alts 1 and 3, 
by an average of $0.01 \mathrm{ft}$. The setup with the channel installed can be $0.06-0.07 \mathrm{ft}$ less without significant shoaling in Pelekane Bay during the storms.

The calculated results show variations of consistent wave setup in Pelekane Bay from October to December 1992. Beginning 6 January 1993, appear significant changes in WSE differences that are related to storm-induced channel or bay infilling. Figure 10 shows the 3-month averaged WSEs for the channel alternatives along the section from E1 to E4. In Kawaihae Harbor, WSE is not affected by installation of a channel. Starting from E2 through the channel and into the bay, water level starts to rise under channel alternatives. Similar to the features of the non-storm condition, less water level setup is presented under the deeper channel alternatives (Alts 2 and 4), and greater setup under the shallower channel alternatives (Alts 1 and 3) in Pelekane Bay. The water rise along the section results in an average water level difference of 0.04-0.06 ft between Pelekane Bay and Kawaihae Harbor.

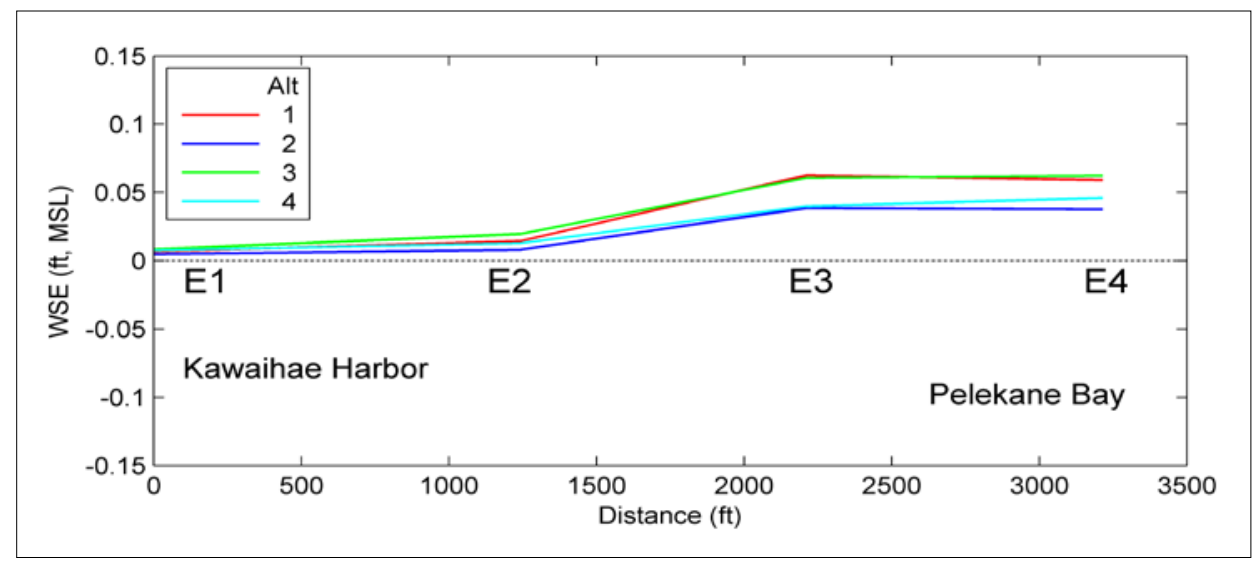

Figure 10. Temporally averaged water surface elevation (October-December 1992) along section composed of four stations from Kawaihae Harbor to Pelekane Bay, as shown in Figure 5.

The existing condition produces the largest water level setup in Pelekane Bay as compared to the alternatives. The water elevation difference between the bay and the harbor is about $0.3 \mathrm{ft}$ for the 7 January 1993 storm. Depending on storm strength, measured by the significant wave height (Table 3), the WSE differences vary from 0.12 to $0.26 \mathrm{ft}$ under the four channel alternatives. The weakest storm (judged by wave height), on 30 January 1993, produces the smallest water level setup and the strongest storm, starting on 7 January 1993, generates the largest.

\section{Current}

Vertically averaged circulation fields surrounding Kawaihae Harbor and Pelekane Bay were analyzed for the five winter storms. Although circulation patterns during the winter storms resemble the snapshot analyzed during the spring swells (Figure 7), three differences are noted:

1. The maximum current speed, mostly occurring outside the breakwater near the small boat harbor, can reach $4.5 \mathrm{ft} / \mathrm{sec}$ during the 7 January 1993 storm. The peak speed along the proposed channel during this storm can be as large as $1.5 \mathrm{ft} / \mathrm{sec}$.

2. The northwest swells associated with winter storms generate a strong alongshore current north of the harbor entrance, flowing towards the harbor. A weaker subcurrent of the alongshore current flows into the harbor and forms a harbor-scale clockwise gyre with a maximum speed exceeding $1 \mathrm{ft} / \mathrm{sec}$.

3. The weak gyre appearing in the inner Pelekane Bay during the spring swells is not observed during winter storms.

The time series reveal three distinct flow patterns that correspond to three periods under the influence of winter storms and the different channel alternatives. The first period is between 1 October 1992 and 9 January 1993, as the 7 January swells just pass the study domain; the second period is between 9 January and 7 February 1993, after the 6 February storm; and the third period is between 7 February 1993 and the end of the simulation.

Temporally averaged along-channel flow is the strongest from Pelekane Bay to Kawaihae Harbor during the first period. The averaged flow speed is $0.24 \mathrm{ft} / \mathrm{sec}$ for Alts 1 and 2, and 0.38 and $0.41 \mathrm{ft} / \mathrm{sec}$ for Alts 3 and 4 with the maximum speed above $1.0 \mathrm{ft} / \mathrm{sec}$ on 7 January 1993. The peak speeds during 
the period correspond well with northwest swells with a significant wave height of about $4.5 \mathrm{ft}$ and larger. Occasional small or negative (harbor-to-bay) flow corresponds to waves propagating from north to east. The along-channel speeds are reduced significantly under Alts 1 , 3, and 4 for the second period, and close to zero under all four alternatives for the third period. This decrease in flow speed is an indication of different extent of channel blockage by frequent passages of northwest swells and swellinduced sediment movement.

\section{Sediment transport}

Morphology changes in Pelekane Bay and the proposed channel are calculated under the existing condition and the proposed channel alternatives at the end of the storm simulations. The spatial distributions for Alt 1 are shown in Figure 11. Under the existing condition, erosion appears between the outer and the inner Pelekane Bay, and deposition appears in the inner bay, both occurring within a small area. Relatively weak circulation in the inner bay should be the reason for weak sediment transport. The channel installation, however, changes the patterns of sediment transport in the bay. Stronger and more persistent currents from the bay to the harbor can transport eroded sand near the outer bay and result in greater deposition in the vicinity of the channel mouth. Under significant different alternatives, deposition can occur and reaches 500-600 ft into the channel. Different from the 15-day results of the non-storm condition, erosion and deposition patterns seem to be associated with channel depth. Eroded sand travels much further into the channel under Alts 2 and 4 than under Alts 1 and 3.

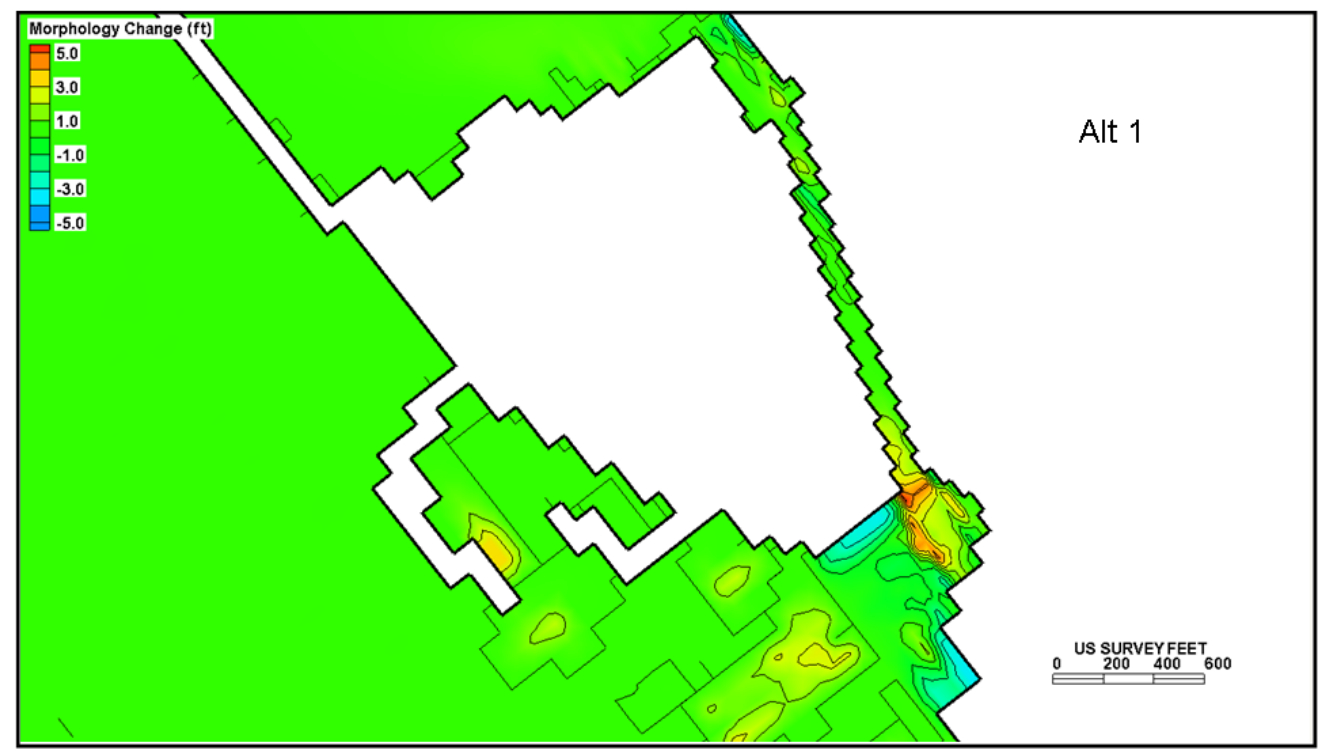

Figure 11. Morphology change under Alt 1 after 6-month simulation.

The maximum calculated erosion and deposition are approximately 4.6 and $6.6 \mathrm{ft}$, respectively, and mostly occurs in Pelekane Bay. The maximum deposition in the channel ranges approximately between 2.3 and $6.6 \mathrm{ft}$ under different alternatives at the end of the simulation. For the same width, a deeper channel alternative (Alts 2 and 4) would more than double the maximum deposition in the channel and sediment volume transported from the bay into the channel, than for a shallow channel alternative (Alts 1 and 3). The volume of sand that would have to be dredged after a similar 6-month period to reestablish the designed channel depth is 1,730 cu yd for Alt 1 and close to 9,000 cu yd for Alt 4 .

Time series of depth change for the four channel alternatives indicate that a few rapid increases in erosion and deposition correspond to some northwest swells propagating into the study area. For example, the 7 January 1993 storm causes $0.2 \mathrm{ft}$ of erosion under Alts 2 and 4 near the channel mouth and 0.2-0.5 ft of deposition in the channel. Starting from 27 January 1993 (an unlisted storm with a wave height of $6.2 \mathrm{ft}$ ) through the 30 January and the 6 February storms, large deposition occurs at the bay and in the channel during the 11-day period. The depth change in the bay is $0.8-2.4 \mathrm{ft}$ under Alts 3 and 4. In the channel, the change is up to $2.9 \mathrm{ft}$ under Alt 4. For Alts 2 and 4, the channel is essentially 
blocked and for Alts 1 and 3, a large amount of sand is either deposited near the channel mouth and/or in the bay, and no sand is transported into the channel after this storm.

\section{CONCLUSIONS}

The CMS, a coupled wave, flow and sediment transport numerical modeling system was applied to evaluate the installation of a proposed circulation channel connecting Kawaihae Harbor to Pelekane Bay on the western side of the island of Hawaii. Sensitivity tests with the CMS reveal that the nearshore harbor area is located in an environment dominated by wave-driven currents, and wind and tidal forcing are secondary.

Four channel alternative configurations were developed and simulated. The numerical modeling analysis examined and quantified potential functioning of the proposed channel, assessed change in water circulation in response to wave conditions and hydrodynamics, and estimated potential sediment transport and morphology change in the vicinity of the channel.

CMS calculations indicate that significant wave setup appears in Pelekane Bay in comparison to that in Kawaihae Harbor. The setup difference is created by southwest to northwest incident waves and is greater under the existing condition than that under the channel alternatives because water cannot flow out of the bay without the channel. During swell, the greater setup under the existing condition is about 0.06-0.07 ft. Generally, deeper channel alternatives correspond to lower setup.

Differential wave setup results in consistent higher WSE in Pelekane Bay than in Kawaihae Harbor. Under the four channel alternatives, the temporally averaged elevation difference between the bay and the harbor ranges from 0.04 to $0.1 \mathrm{ft}$, and the value ranges from 0.12 to $0.26 \mathrm{ft}$ during typical winter storms.

Circulation patterns surrounding Kawaihae Harbor are produced by the incident waves, but do not exhibit much variability with the installation of the proposed channel. The only area in which circulation could be affected by the channel is in inner Pelekane Bay. Due to differential wave setup between Pelekane Bay and Kawaihae Harbor, water in the proposed channel is predicted to flow from the bay to the harbor in nearly all of the alternatives modeled. The exceptions are some short periods of flow reversal associated with waves propagating from north to east. Without consideration of channel and bay infilling, temporally averaged along-channel flow speed ranges from 0.24 to $0.62 \mathrm{ft} / \mathrm{sec}$, and the maximum speed can exceed $1.5 \mathrm{ft} / \mathrm{sec}$ during a winter storm. Comparing channel alternatives, a wider channel, Alts 3 and 4, corresponds to stronger along-channel current speed and a narrower channel, and Alts 1 and 2, to weaker current speed.

The spatial distributions of morphology change indicate weak and limited transport of sand under the existing condition in Pelekane Bay. However, with channel installation, flow erodes sand from Pelekane Bay and transports it to the mouth of and inside the proposed channel. Calculated time series of depth change at selected bay and channel stations show a steady deposition of sand, and that storms are a major cause in contributing to sand transport and accumulation (blockage of the channel). At the end of the multi-storm simulations, the predicted maximum deposition is greater than $6.0 \mathrm{ft}$, both in the bay and the proposed channel. More sand is deposited in the channel under the deeper channel alternatives, Alts 2 and 4. The channel or bay blockage appears under all four channel alternatives before the end of a 6-month simulation. To reestablish the designed channel depths following the 6-month simulation, the minimum amount of sand that would have to be dredged from the channel is $1,730 \mathrm{cu}$ yd for Alt 1 , and the maximum amount of sand is close to 9,000 cu yd for Alt 4 .

\section{REFERENCES}

Aucan, J. 2006. Directional wave climatology for the Hawaiian Islands from buoy data and the influence of ENSO on extreme wave events from wave model hindcast. $9^{\text {th }}$ International Workshop on Wave Hindasting and Forecasting. Victoria, B.C.: Canada.

Bodge, K. R., and Howard, S. 2006. Groins, headlands, and cutting an island in two in the Maldives. Proceedings $30^{\text {th }}$ International Conference on Coastal Engineering 2006, Vol. 4. San Diego, CA, 3-8 September, 3,656-3,668.

Buttolph, A. M., C. W. Reed, N. C.Kraus, N. Ono, M. Larson, B. Camenen, H. Hanson, T. Wamsley, and A. K. Zundel, A. K. 2006. Two-dimensional depth-averaged circulation model CMS-M2D: Version 3.0, Report 2, sediment transport and morphology change. Coastal and Hydraulics Laboratory Technical Report ERDC/CHL-TR-06-7. Vicksburg, MS: U.S. Army Engineer Research and Development Center.

Camenen, B., and M. Larson. 2005. A bedload sediment transport formula for the nearshsore. Estuarine, Coastal and Shelf Science 63:249-260. 
Camenen, B., and M. Larson. 2008. A general formula for noncohesive suspended sediment transport. Journal of Coastal Research 24(3):615-627.

Coastal and Hydraulics Laboratory. 2009. Wave Hindcasts. http://www.frf.usace.army.mil/cgibin/wis/atl/atl_main.html.

College of Tropical Agriculture and Human Resources. 2001. Pelekane Bay Watershed Project, Phase V. Honolulu, HI: Hawai'i Water Quality Extension Program, College of Tropical Agriculture and Human Resources, University of Hawai’I at Mānoa.

Goda, Y. 1973. A new method of wave pressure calculation for the design of composite breakwaters. Report of the Port and Harbor Research Institute 12(3).

Hawaiian Images Photography \& Video. 2009. Aerial photography - scenic photos of Big Island. http://www.hawaiianimages.net.

Lin, L., Z. Demirbilek, H. Mase, J. Zheng, and F. Yamada. 2008. CMS-Wave: A nearshore spectral wave processes model for coastal inlets and navigation projects. Coastal and Hydraulics Laboratory Technical Report ERDC/CHL-TR-08-13. Vicksburg, MS: U.S. Army Engineer Research and Development Center.

National Data Buoy Center. 2009. Historical meteorological data. http://www.ndbc.moaa.gov.

National Geophysical Data Center. 2009. Bathymetry, topography and relief. http://www.ngdc.noaa.gov/mgg/bathymetry/relief.html.

State of Hawaii Department of Transportation. 2009. Port Hawaii Handbook. Honolulu, HI: Harbors Division, Department of Transportation, State of Hawaii.

Thompson, E. F., Z. Demirbilek, and M. J. Briggs. 2006. Wave climate and wave response, Kawaihae Deep Draft Harbor, Island of Hawaii, Hawaii. Coastal and Hydraulics Laboratory Technical Report ERDC/CHL-TR-06-6. Vicksburg, Mississippi: U.S. Army Engineer Research and Development Center.

Tissot, B. N. 1998. Changes in the marine habitat and biota of Pelekane Bay, Hawaii, over a 20-year period. Technical Report. Honolulu, HI: U.S. Fish and Wildlife Service, Pacific Islands Office.

Wozencraft, J. M., and W. J. Lillycrop. 2002. SHOALS airborne coastal mapping: Past, present, and future. Journal of Coastal Research SI(38):207-215. 